\title{
El papel de la Ética y los Valores en la enseñanza del Derecho
}

\section{The Role of Ethics and Values in Law Teaching}

Sergio Lugo-Ortiz ${ }^{a}$, Robertha Trejo-Hernández ${ }^{b}$

\begin{abstract}
:
On the following pages is discuss the role of ethics and values in university education and specifically in the law education program (ethical and value formation). It is emphasized that in addition to the ethical and moral nature of education, universities, like any educational institution, seek to promote a series of values in accordance with their institutional mission and each of their educational programs. Finally, the social sense of education and values is proposed as a necessity to influence social problems.
\end{abstract}

Keywords:

Ethics, morals, values, axiology, public ethics

Resumen:

En las siguientes páginas se discute el papel de la ética y los valores en la educación universitaria y en específico del programa educativo de derecho, (Formación Ética y Valoral). Se subraya que además de la naturaleza ético-moral de la educación, las universidades, como toda institución educativa pretenden impulsar una serie de valores acordes con su misión institucional y de cada uno de sus programas educativos. Por último, se propone el sentido social de la educación y los valores como una necesidad para incidir en las problemáticas sociales.

Palabras Clave:

Ética, moral, valores, axiologia, ética pública

\section{Introducción}

En estos momentos el siglo XXI representa nuevos desafíos para la humanidad. La crisis mundial de salud, problemas económicos, sociales y ambientales. La pandemia ha transformado las relaciones entre las personas, dando lugar a una nueva forma de ver y comprender el mundo según la cual los grandes problemas deben ser resueltos por ciudadanos comprometidos, socialmente responsables, con el cuidado de la salud y el planeta que actúan de manera proactiva, hoy más que nunca se hacen necesarios los valores. Las universidades tienen el papel fundamental de ser semilleros de formación de personas críticas y propositivas frente a las problemáticas sociales de su entorno, imbuidos por valores. La educación juega un papel fundamental para la enseñanza de estos; como parte de las características que el alumno debe de ir adquiriendo en su proceso formativo para desarrollar un perfil profesional que responda a las exigencias de su entorno y de manera indirecta en la práctica cotidiana de las actividades académicas o en el desarrollo de las relaciones sociales en el aula, la educación es entendida como un proceso en donde el alumno se apropia de conocimientos, habilidades y aptitudes y valores y como tal la educación tiene muchos significados, y se le han agregado un sinfín de adjetivos como educación: integral, en valores, democrática, etc., la educación cumple una función la cual depende del contexto que se le asigne: educación permanente, formación cívica, desarrollo de la identidad y personalidad, formación profesional. Para nuestro trabajo tomaremos dos: educación y valores. Estableciendo un punto de inicio diremos que la Universidad Autónoma del Estado de Hidalgo (UAEH) se ha planteado como como objetivo la formación integral de sus estudiantes, "fomentando la solidaridad social (...)

${ }^{a}$ Autor de Correspondencia, Universidad Autónoma del Estado de Hidalgo, Email: sergio_lugo6844@uaeh.edu.mx

b Centro Universitario Vasco de Quiroga de Huejutla, Escuela Normal de las Huastecas, Email: roberta.trejo@normalhuastecashidalgo.edu.mx 
fomentar la legalidad, transparencia y protección de los derechos humanos" (misión UAEH), este imperativo puntualiza considerar la importancia del papel de los valores implícitos en la formación de los alumnos y de manera específica del Programa Educativo (PE) de Derecho, el cual ha establecido en su misión "formar profesionales del Derecho, (...) con un alto respeto por los valores éticos fundamentales, con un claro sentido ético humanista" (visión PE Derecho UAEH), el alumno, no puede desligar de su actuación esta carga ética y de valores presente en su quehacer académico cotidiano, es necesario para poder hablar de esa formación integral, hablar del papel de los valores en la formación de los estudiantes universitarios del PE de Derecho de la UAEH.

\section{Acercamiento conceptual.}

Es pertinente hacer un acercamiento conceptual tanto de Ética y Moral como de Valores; los términos ética y moral, son usados como sinónimos derivados de sus significados etimológicos, donde la palabra ética viene del

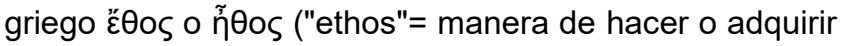
las cosas, costumbre, hábito) más el sufijo-ıкos (-ico = relativo a). Se refiere a la rama de la filosofía que estudia la moral y la manera de juzgar la conducta humana, el carácter y el modo de ser; êthos, primitivamente, significaba estancia, lugar donde se habita, Aristóteles retomo el sentido de la palabra griega y a partir del significado manera de ser, la ética era como una segunda casa o naturaleza; una naturaleza lograda, no transferida (información genética heredada), así una persona puede moldear, forjar o construir su modo de ser o êthos. La palabra moral viene del latín "moralis Los romanos parece que tradujeron ṅӨıкós a moralis, a partir de la palabra

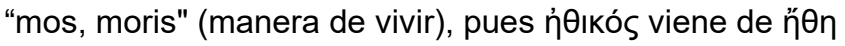
("ethes" = costumbre, carácter, manera de adquirir las cosas). Así "moralis" tiene un significado referente a las costumbres que significa también "carácter o modo de ser". Sucede lo mismo con la definición etimológica de valor tomaremos la referencia de origen griego, axio (axios) significa en primer lugar "valor, dignidad", que es digno o que merece el mérito, el aprecio de honra, representa lo recto, justo o que es conveniente de realizar en segundo lugar proviene del desglose de "actio", esta es una palabra latina que hace referencia a una acción, es decir, que se tiene la posibilidad de crear un acto de honra. A partir de axios= acción "el hombre es libre, responsable y sin excusas", según Jean Paul Sartre, surgen como parte de un axio, en este contexto, podemos hacer referencia al vocablo derivado del latín "valor, valōris", entendido, como la cualidad conferida a hechos, cosas o personas, esta valoración puede ser por ejemplo desde el punto de vista estético o ético (negativa o positiva); en el ámbito de la filosofía, la axiología es una de sus ramas que se encarga del estudio completo de la naturaleza y juicio del valor, del griego "áłı

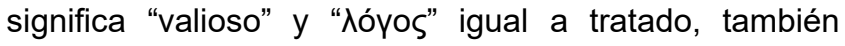
conocida como filosofía de los valores. El término fue utilizado preferentemente en el ámbito de la reflexión ética, desplazando el uso de términos como "bien" y "bueno". En este sentido, el valor es aquella cualidad que apreciamos en un objeto moral (cuando hablamos aquí de "objeto moral" nos referimos a la acción la cual está dotada de una intencionalidad siendo el fin de determinado de manera libre); es decir, es una cualidad, no una cosa; y se manifiesta en relación con la actuación del ser humano, que hace palpable dicha cualidad. Para clarificar, ética en relación con la moral y los valores es una reflexión sobre esta, la cual permite calificar los actos humanos a partir de códigos de valores (juicios de valor) convirtiendo en deseables estas acciones; es pertinente agregar a este análisis las teorías éticas para dar aún más luz sobre el papel de la ética en el individuo y en este caso en los alumnos en la figura 1 se muestra un mapa conceptual en donde agrupamos a las teorías éticas en dos grandes grupos, el primero las éticas materiales donde ubicamos a filósofos como Sócrates, Epicuro, Zenón, Stuard Mill y Max Sheler y el segundo grupo la ética formal ubicando filósofos como Immanuel Kant, Jean Paul Sartre, George E. Moore, Alfred Ayer y Richar Are, desde estas perspectivas, propuestas por las diferentes teorías éticas tratan de ofrecer una justificación de las actuaciones y su carácter moral, presentando un modelo ideal de moralidad, de una vida virtuosa y acorde con códigos de valores. Una vez comprendida esta dificultad polisémica originada por sus similitudes de significación etimológica, y la diversidad de perspectivas teóricas, orientemos el análisis hacia la ética pública por lo que haremos referencia a la definición de M. Villoria Mendieta:

"La ética pública trata de definir lo que está bien y mal para la colectividad, aquello que podría constituir un patrón moral básico de carácter universal y generalizable, dado lo racional y razonable de sus fines, valores y prescripciones de conducta, patrón compatible con la propia búsqueda razonable del bien." (2002:663) 


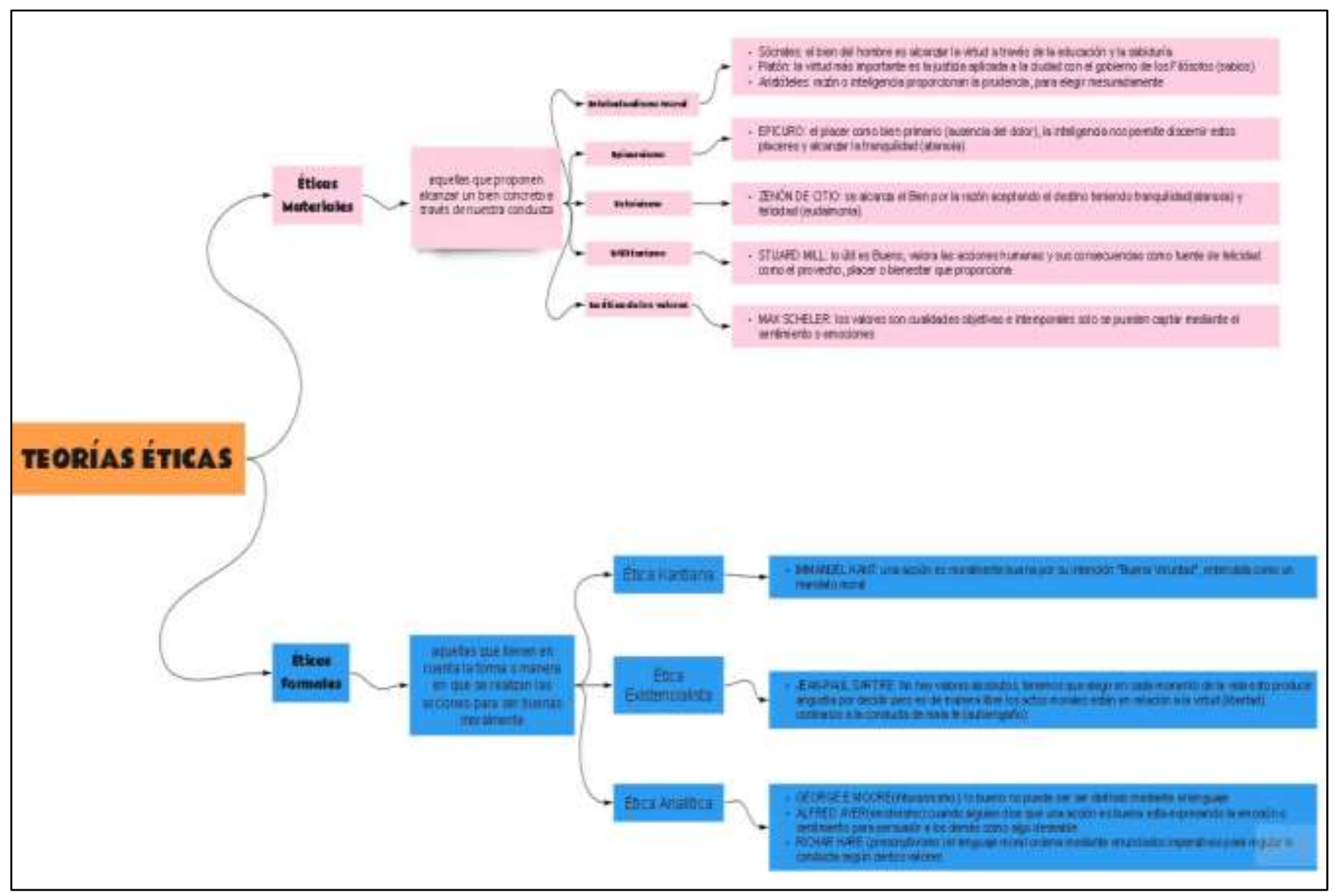

Fuente: elaboración propia

Definición que considero con mayor propiedad para guiar nuestro análisis en un contexto organizacional, en este caso Universitario puesto que esta tiene como finalidad contribuir con el desarrollo de la sociedad en términos de mejorar la calidad de vida y yo lo diría teniendo en cuenta en contribuir a la formación integral de nuestros alumnos como parte de una comunidad, inculcando valores en ellos. Desde estas diferenciaciones, Ética se refiere a la disciplina filosófica que constituye una reflexión sobre los problemas morales. Moral, es el conjunto de principios, normas y valores que cada generación trasmite a la siguiente, (Yolimar 2012:234), fundamentando esta forma de ser y actuar en "lo bueno y lo justo". y los valores entendidos como aquellos que orientan a las personas sobre qué deben poner en práctica para conducir su vida de un modo bueno y justo; Yegres apunta: "Por Valores a aquellas formas de ser y de actuar de las personas que son altamente deseables como atributos o cualidades nuestras y de los demás" (2007:36), en este contexto toda organización crea y establece una dimensión filosófica en donde se plasman los valores propuestos por ella misma, como parte del ideario que debe permear a la formación de la identidad y ser un elemento intrínseco en las acciones o actuaciones de sus miembros, como lo podemos constatar en ejemplos claros desde lo particular en el día a día como maestros, en el aula al impartir nuestra clase, como alumnos al cumplir con sus tareas, la estructura administrativa que crea un perfecto clima organizacional y en general como nos conducimos todos los miembros de la comunidad universitaria al relacionarnos e influir en la sociedad como líderes éticos y propositivos, y responder así de manera clara y precisa a esta Misión y Visión; a través de la práctica de: los valores de la integridad académica, los valores universitarios, y los valores universales, los valores como parte del perfil profesional del Licenciado en Derecho.

\section{Modelo educativo de la UAEH y su Código de ética}

El Modelo Educativo conforma un estado de referencia permanente sobre el cual se articulan los procesos sustantivos y adjetivos de la Universidad. De acuerdo con el modelo educativo la docencia es 
...La docencia es la función sustantiva que permite relacionar todos los conceptos ya descritos, bajo el amparo de la libertad de cátedra; resume las corrientes educativas; hace uso de los enfoques, las escuelas de pensamiento educativo, la intencionalidad, la perspectiva sociológica, pedagógica y filosófica (Modelo Educativo UAEH 2015:58) Dicho esto, el docente tiene que estar en contacto permanente con sus estudiantes y tiene que desarrollar en ellos habilidades, aptitudes y valores. Los valores universitarios, son guía para el actuar dentro y fuera de la UAEH, de esto se desprende la idea de que la universidad nos forma para el resto de nuestra vida "profesional". El Modelo Educativo Universitario resume el Ser y Quehacer de nuestra institución, por ello, además de ser una norma aprobada por el Consejo Universitario, es fuente de múltiples referencias para comprender mejor los fines de la UAEH, en donde los valores plasmados en su dimensión filosófica (Tabla 1), reúnen el ideario de la institución, sus valores y deberes, constituyéndose en el entorno ético que sirve de marco a la deontología de los integrantes, es decir son esas pautas que deben estar presente en cada uno de los integrantes de la comunidad universitaria.

Tabla 1: Principios y valores universitarios del Modelo Educativo

\begin{tabular}{|c|c|}
\hline $\begin{array}{l}\text { Principios } \\
\text { universitarios }\end{array}$ & $\begin{array}{l}\text { Acciones de la comunidad } \\
\text { universitaria }\end{array}$ \\
\hline $\begin{array}{l}1 . \\
\text { Responsabilidad }\end{array}$ & $\begin{array}{l}\text { Como profesores, investigadores o } \\
\text { alumnos tenemos la } \\
\text { responsabilidad y el deber de } \\
\text { cumplir con las funciones que nos } \\
\text { ha sido encomendadas, con la } \\
\text { convicción de hacerlo lo mejor } \\
\text { posible poner el empeño para } \\
\text { lograr las metas institucionales. }\end{array}$ \\
\hline $\begin{array}{l}\text { 2. La } \\
\text { honestidad }\end{array}$ & $\begin{array}{l}\text { Desarrollar nuestro trabajo en un } \\
\text { marco de transparencia y apegado } \\
\text { a las normas institucionales. }\end{array}$ \\
\hline 3. El respeto & $\begin{array}{l}\text { El trato respetuoso con los } \\
\text { compañeros de trabajo y con los } \\
\text { usuarios de nuestros servicios. }\end{array}$ \\
\hline $\begin{array}{ll}4 . & \mathrm{El} \\
\text { compromiso } & \end{array}$ & $\begin{array}{l}\text { Asistir puntualmente a impartir una } \\
\text { enseñanza efectiva y lograr que } \\
\text { nuestros alumnos aprendan las } \\
\text { competencias profesionales que se } \\
\text { requieren para cumplir con los } \\
\text { objetivos de los programas } \\
\text { educativos. }\end{array}$ \\
\hline 5. La lealtad & $\begin{array}{l}\text { Llevar una conducta de apego a los } \\
\text { intereses de la institución con ese } \\
\text { sentido de pertenencia. }\end{array}$ \\
\hline 6. El amor & $\begin{array}{l}\text { Implica la generosidad con el otro, } \\
\text { con nuestro trabajo, el gusto y el }\end{array}$ \\
\hline
\end{tabular}

\begin{tabular}{|c|c|}
\hline & $\begin{array}{l}\text { placer de compartir nuestro trabajo } \\
\text { y ayudar al a los demás (alumnos y } \\
\text { colegas). }\end{array}$ \\
\hline 7. La tolerancia & $\begin{array}{l}\text { Ser tolerantes es respetar al otro } \\
\text { con sus diferencias, sus tiempos, } \\
\text { su libertad, su pensamiento y } \\
\text { características. }\end{array}$ \\
\hline 8. La probidad & $\begin{array}{l}\text { Tener un comportamiento } \\
\text { coherente, justo, legítimo y } \\
\text { ejemplificante con nuestros actos, } \\
\text { justos, equitativos, atentos, } \\
\text { generosos. }\end{array}$ \\
\hline 9. La fraternidad & $\begin{array}{l}\text { Significa que como miembros de la } \\
\text { institución tenemos algo que nos } \\
\text { une y pueden ser sus ideales, sus } \\
\text { proyectos, sus propuestas, su } \\
\text { modelo, algo que nos unifica como } \\
\text { persona y como organización. }\end{array}$ \\
\hline $\begin{array}{l}\text { 10. El sentido } \\
\text { del deber }\end{array}$ & $\begin{array}{l}\text { Un modo de ser que distingue a las } \\
\text { personas y a sus compromisos. }\end{array}$ \\
\hline $\begin{array}{ll}11 . & \mathrm{La} \\
\text { cooperación } & \end{array}$ & $\begin{array}{l}\text { Sin duda las acciones en nuestra } \\
\text { actividad académica constituyen } \\
\text { un elemento esencial el trabajo } \\
\text { colaborativo y cooperativo. }\end{array}$ \\
\hline $\begin{array}{ll}12 . & \text { La } \\
\text { solidaridad } & \end{array}$ & $\begin{array}{l}\text { Es algo que está presente, ante } \\
\text { una circunstancia difícil y ofrecer la } \\
\text { ayuda necesaria para solucionar } \\
\text { los problemas. }\end{array}$ \\
\hline 13. El orden & $\begin{array}{l}\text { Nace de la conciencia del bien } \\
\text { colectivo que del sometimiento a } \\
\text { un sistema ya dado. }\end{array}$ \\
\hline 14. El honor & $\begin{array}{l}\text { Como docentes debemos ser } \\
\text { respetuosos de la vida de las otras } \\
\text { personas, y conducirnos de una } \\
\text { forma correcta. }\end{array}$ \\
\hline 15. La disciplina & $\begin{array}{l}\text { Los buenos hábitos, las buenas } \\
\text { conductas y, en última instancia, la } \\
\text { rectitud con que se vive en la } \\
\text { institución de forma constante y } \\
\text { habitual. }\end{array}$ \\
\hline $\begin{array}{l}\text { 16. La vocación } \\
\text { para paz }\end{array}$ & $\begin{array}{l}\text { Considerar todos los valores nos } \\
\text { hace estar en paz con uno mismo y } \\
\text { con los demás y en armonía con el } \\
\text { entorno. }\end{array}$ \\
\hline
\end{tabular}

Fuente: elaboración propia de acuerdo con los principios y valores del modelo educativo de la UAEH.

Otro documento que es fundamental mencionar es el CÓDIGO DE ÉTICA E INTEGRIDAD ACADÉMICA DEL PERSONAL Y EL ALUMNADO DE LA UNIVERSIDAD AUTÓNOMA DEL ESTADO DE HIDALGO (2019) en el que se plasman un cumulo de valores que son fundamentales para las actividades académicas, el cual tiene como objetivo según su artículo 1.1: 
El Código de Ética e Integridad Académica prescribe las normas que contienen los valores y los principios que fundamentan el liderazgo ético y la integridad académica a partir de un sentido de responsabilidad ante la sociedad nacional y global, así como ante la comunidad universitaria internacional; de manera complementaria y para lograr que la comunidad universitaria se apropie de los principios y valores éticos de este código, la UAEH a través de la Dirección de Superación Académica ha creado algunos cursos 0 diplomados como por ejemplo: Integridad Académica en la Comunidad Universitaria, para que el claustro de maestros en su quehacer cotidiano en la docencia transmitan los valores (como principios rectores) a toda la comunidad universitaria, con el fin de formar agentes de cambio capaces de transformar su entorno social, innovando y generando conocimiento bajo una perspectiva humanista.

Estos dos documentos establecen un conjunto éticonormativo que determina el quehacer de la universidad, es decir que estas pautas establecen el ser y el deber ser que controlan las acciones de las personas o conductas organizacionales, así como establecen los valores que deben ser respetados y considerados por todos integrantes de la comunidad universitaria, y por ende estos valores se encuentran de manera explícita e implícita en cada uno de los programas educativos de la UAEH, al ser trasmitidos por el docente dentro del aula al ser el facilitador y evaluar el desempeño de los alumnos en cuanto conocimientos, habilidades y actitudes (practica de los valores ).

\section{Los valores en perfil del PE de Derecho}

En el perfil de ingreso el aspirante de este PE debe contar con sólidos conocimientos y un bagaje cultural necesario para el desarrollo académico, aunado a las habilidades y actitudes, pero es fundamental que se encuentren presentes los siguientes valores: Responsabilidad para su formación profesional. Ética (como el conjunto de principios y valores deseables para la convivencia). tolerancia y solidaridad; en el perfil progresivo en donde

\footnotetext{
${ }^{1}$ Con el rediseño educativo del PE de Derecho en el año 2015 la malla curricular no contiene una asignatura que contemple la formación ética, como ética Jurídica o deontología jurídica, aunque se integra la asignatura de Derechos Humanos que de acuerdo a su contenido temático se abordan temas como la seguridad Jurídica, la Dignidad Humana, la no discriminación, la equidad, la igualdad, la libertad de expresión, mismos que se hacen valer a través del juicio de Amparo en caso de una omisión o acción de una autoridad incluso de norma general que pretende limitar dichos derechos. Metodología jurídica donde a través de la investigación jurídica tiene como fin la búsqueda por la verdad, como parte del núcleo de formación profesional del Licenciado y Licenciada en Derecho.
}

se adquieren el conjunto de características que el estudiante desarrolla a través de la vivencia y acreditación de las asignaturas que conforman núcleos de formación y ejes temáticos ${ }^{1}$, dotando al alumno de una capacidad para cumplir a cabalidad los valores del Derecho como la justicia, la seguridad jurídica, la búsqueda por la verdad, la equidad, el bien del Ser Humano, concretizándose en un tercer corte que lo representan los semestres de $7 \mathrm{mo}$ y $8 \mathrm{vo}$ en donde práctica los valores éticos fundamentales ${ }^{2}$ y del ecosistema con un claro sentido humanista; aunque no existe de manera específica una asignatura sobre derecho ecológico se ha establecido una política ambiental que forma parte del Sistema Integral de Gestión Institucional. Con el Perfil de egreso los egresados pondrán en práctica los valores fundamentales del ser humano, los valores jurídicos del Estado Mexicano y el ethos de la Universidad Autónoma del Estado de Hidalgo, para fomentar la transparencia, la rendición de cuentas, la legalidad y consolidar a nuestra Democracia con el objeto de tener una mejor convivencia social y como reza en nuestro lema "Amor, Orden y Progreso", fundamentos en los que creemos y a partir de las cuales nos conducimos: AMOR como principio, ORDEN como fortaleza y PROGRESO como resultado.

\section{Sentido social de la educación}

El conocimiento y la información son fundamentales para el desarrollo de la sociedad en su constante transformación es imposible transitar de un estado a otro sin la educación o el aprendizaje de conocimientos y reglas que esta trasmite a los individuos; Como seres humanos siempre tendremos diferencias, y esas diferencias son las que debemos potenciar para mejorar nuestra propia existencia y la de la sociedad; de ahí que se desprenda cual es el papel de la educación y el papel de los valores en la formación de los individuos. El individuo desde muy pequeño está en contacto con el aprendizaje por lo que es pertinente mencionar, a los agentes que influyen en su formación, son la familia, la escuela, medios de comunicación y grupos culturales, en ellos la familia y la escuela tienen un carácter formal e

2 Es importante mencionar en este contexto, el Decálogo del Abogado de Eduardo J. Counture, cuyos postulados son: Estudia, Piensa, Trabaja, Lucha, Sé leal, Tolera, Ten paciencia, Ten Fe, Olvida y Ama a tu profesión. También se le Conoce como los Diez Mandamientos del Abogado, que permite a estudiantes y profesionistas del derecho hacer una concientización de lo que realmente significa el ser abogado y la responsabilidad de conducirse íntegramente en el desempeño de la profesión. 
institucional, se puede decir que la familia es la primera institución socializadora, en ella nace y se educa al niño principalmente en valores que le permitirán insertarse en la sociedad, posteriormente la escuela es el sitio en el que los niños, adolescentes y jóvenes, interaccionan con el medio social además de los lazos que tienen con sus familiares cercanos. Durante este proceso formativo el individuo convive, experimenta y aprende. Cada contexto familiar es diferente y pueden que haya ejercido influencias positivas y negativas, en su formación y la adquisición de su ethos (el ser y actuar), Vygotsky establece que Los niños y para nosotros los jóvenes desarrollan su aprendizaje mediante la interacción social, van adquiriendo nuevas y mejores habilidades socio cognoscitivas como proceso lógico a un modo de vida, el desarrollo sigue al aprendizaje y no viceversa. Es decir, para que haya desarrollo en los alumnos, ellos tienen que primero aprender y este se produce en situaciones sociales significativas (Vygotsky, 1979, p. 94), aquellas actividades que se realizan de forma compartida le permiten interiorizar las estructuras de pensamiento y comportamentales de la sociedad que les rodea, apropiándose de ellas. La universidad es la institución educativa que pretende que el proceso de socialización del conocimiento tenga un papel fundamental en la educación e inserción social como profesionistas que puedan incidir y resolver los problemas sociales. La educación superior tiene un lugar importante en la sociedad, ya que la universidad puede estar presente en diversos contextos ya sean rurales 0 urbanos permitiéndole interrelacionarse con su entorno, a su vez, se debe establecer un acercamiento del entorno hacia la institución y desde esta se puede facilitar el acercamiento a la comunidad a través de actividades como tareas a la mejora de la comunidad para reforzar lazos con la sociedad como se establece en el perfil de egreso en PE de Derecho, el cual pretende formar de manera integral a estudiantes que puedan incorporarse en el campo laboral, así como participar eficazmente en los ámbitos social y político-jurídico; es necesario que el egresado obtenga un conjunto de conocimientos, competencias, habilidades, actitudes y valores (tabla 2) con la intención de impactar en el desarrollo de su entorno. Una universidad no tiene razón de ser si no está comprometida con la sociedad ya que dejara de preocuparse por problemáticas de su entorno y de integrar a personas que son importantes con la comunidad (creando y fomentando un liderazgo social) Como afirma Juan Delval (2000)

"La escuela no puede llegar a cumplir su misión educativa sin problematizar sobre el contexto social que la rodea, si bien ha de armonizar con la sociedad y, desde ella, seguir trabajando activamente para la mejora de la vida personal y comunitaria".

\begin{tabular}{|c|c|}
\hline $\begin{array}{l}\text { Competencias } \\
\text { específicas }\end{array}$ & $\begin{array}{l}\text { - Comprensión Jurídica } \\
\text { - Análisis Jurídico } \\
\text { - Interpretación Jurídica } \\
\text { - Aplicación Jurídica } \\
\text { - Comprensión Jurídica }\end{array}$ \\
\hline Habilidades & $\begin{array}{l}\text { - Contar con profunda libertad } \\
\text { heurística. } \\
\text { - Capacidad para desarrollar trabajo en } \\
\text { equipo. } \\
\text { - Capacidad de adaptación a } \\
\text { condiciones adversas para el trabajo. } \\
\text { - Capacidad de templanza. } \\
\text { - Creatividad. } \\
\text { - Manejo adecuado del lenguaje oral y } \\
\text { escrito. } \\
\text { - Manejo de la tecnología de punta en } \\
\text { el desempeño de su profesión. }\end{array}$ \\
\hline Actitudes & $\begin{array}{l}\text { - Inquietud intelectual permanente por } \\
\text { la actualización profesional. } \\
\text { - Disciplina para el estudio sistemático } \\
\text { de la Ley y la Jurisprudencia. } \\
\text { - Responsabilidad absoluta en el } \\
\text { desempeño profesional. } \\
\text { - Tolerancia en el trato con las diversas } \\
\text { personas con las que se relaciona } \\
\text { laboralmente. } \\
\text { - Capacidad de reacción para } \\
\text { identificar y resolver problemas } \\
\text { jurídicos y tomar decisiones. } \\
\text { - Compromiso con su trabajo. }\end{array}$ \\
\hline Valores & $\begin{array}{l}\text { - Respeto al orden jurídico establecido } \\
\text { y a los derechos fundamentales. } \\
\text { - Honestidad, lealtad y verdad en el } \\
\text { ejercicio de su actividad profesional. } \\
\text { - Conducta ética en el ejercicio de su } \\
\text { profesión, sobre todo cuando se } \\
\text { involucre el secreto profesional. } \\
\text { - Que en su desempeño profesional } \\
\text { busque la concreción de los valores } \\
\text { jurídicos del Estado mexicano. }\end{array}$ \\
\hline
\end{tabular}

Fuente. Elaboración propia de acuerdo con el documento del rediseño del PE de Derecho 2015.

La educación y la sociedad son dos conceptos estrechamente relacionados, pues ambos están interrelacionados, la universidad colabora en el crecimiento de la sociedad y la sociedad también contribuye a la educación de los alumnos. El modelo para elegir la educación depende mucho de la sociedad del momento, del entorno social y cultural que nos rodea, de ella depende que los jóvenes sean la esperanza para un mejor futuro, Por lo que en el perfil de egreso se precisan 
los saberes que respaldan la formación y desarrollo de las competencias alineadas con los atributos, habilidades y valores enmarcadas en cada asignatura, para dar sentido de pertenencia y compromiso de toda la comunidad educativa que interviene; donde el aprendizaje bajo este enfoque constituye un referente de valor en su vida cotidiana. EI PE de Derecho esta de acorde con la misión y visión de la universidad la cual establece como objetivo fundamental el formar capital humano de alta calidad, de acuerdo con las necesidades de la sociedad global, propiciando la incorporación exitosa de sus egresados al trabajo productivo en el ámbito de su competencia; generar investigación de alta competitividad en beneficio de la sociedad.

A manera de conclusión con lo antes expuesto valores y educación son elementos inseparables ya que cada una influye sobre la otra, teniendo en cuenta que los valores que se tienen como persona y como miembro de una colectividad, se exige (deber ser y actuar) ser una persona íntegra en el ámbito universitario, en donde aprendes este marco valoral, permitiendo internalizar estos códigos de conducta éticos y morales, pasando de lo individual a lo colectivo, producto de las interacciones sociales, y culturales, si el individuo no actúa de acuerdo con los valores de la institución se estaría aislando, no formaría parte de la colectividad universitaria, al no practicar los valores universitarios y los aprendidos a lo largo de su formación profesional buscando responder a las exigencias de la sociedad y a su vez como institución superior responder a estas exigencias adecuando y transformando sus planes de estudio y su oferta educativa y así se cumpla con la misión y visión de la universidad en donde la formación integral del estudiante (intelectual, cultural y valoral) responda a este contexto social. La universidad es la casa donde se aprende y se va moldeando, forjando y construyendo su modo de ser o su êthos como universitario y como profesionista. Una función social primordial de la Universidad es formar Ciudadanos con valores, con una conciencia crítica para comprender y resolver los grandes problemas de nuestro país y del mundo, adiestrar a los profesionales con las habilidades y competencias, conocimientos para propiciar cambios en el entorno social, para lograr un desarrollo cultural de Nación, la Universidad debe velar, promover y garantizar el desarrollo de las libertades, de los Derechos Humanos, de la equidad de género, del respeto al medio ambiente. Cuando el Ser Humano supere los vicios heredados del pasado, como la ignorancia, la desigualdad social, fanatismo, superstición, la tiranía y la hipocresía, además de ser capaz por sí mismo de tomar decisiones (Autonomía), es porque se ha logrado la educación.

\section{Referencias}

[1] Delval, J. (2000). Aprender en la vida y en la escuela. Madrid. Magíster

[2] Universidad Autónoma del Estado de Hidalgo. Síntesis del Modelo educativo de la UAEH. México, Hidalgo: UAEH, 2015.

[3] Universidad Autónoma del Estado de Hidalgo. Programa educativo de la licenciatura en Derecho, Rediseño Curricular. México, Hidalgo: UAEH, 2015.

[4] Vilchez, Yolimar. 1. "Ética Y Moral: Una Mirada Desde La Gerencia Pública.". Revista Arbitrada Formación Gerencial 11 (2). https://produccioncientificaluz.org/index.php/rafg/article/view/656.

[5]Villora Mendieta, Manuel. (2002). ÉTICA PÚBLICA Y CORRUPCIÓN EN EL INICIO DE UN NUEVO MILENIO. 2002.

[6] Vygotsky, L. S. (1979). El desarrollo de los procesos psicológicos superiores. Barcelona: Grijalbo.

[7] Yegres, A (2007). Ética, Política y Educación. Caracas, Venezuela: Ediciones del Doctorado en Educación UPEL-IPC. 